\title{
Desde el aporte local al control de la resistencia bacteriana en Chile
}

Departamento de Medicina Interna, Facultad de Medicina, Pontificia Universidad Católica de Chile, en representación del Grupo Colaborativo de Resistencia Bacteriana Chile.

Correspondencia a: Jaime Labarca Labarca jlabarca@med.puc.cl

\section{L} a resistencia bacteriana es hoy día un asunto mayor de salud pública. El problema ha ido globalmente en aumento y nuestro país no es la excepción. Al igual que en muchos otros países, este fenómeno es extremo en los establecimientos hospitalarios, especificamente en los de mayor complejidad y en todas las unidades de pacientes críticos, pero también está presente en la comunidad.

Permanentemente se están describiendo nuevos mecanismos de resistencia incluso a antimicrobianos que recién ingresan al uso clínico, de tal manera que el problema parece inagotable. Por otro lado, hay muy pocas alternativas terapéuticas actualmente disponibles para las bacterias multi-resistentes más frecuentes en nuestro medio.

Está claramente demostrado el tremendo impacto en mortalidad, morbilidad y costos asociado a la atención de estas infecciones. La solución claramente no está por el lado de crear nuevos antimicrobianos, pues, de hecho, la investigación en nuevos fármacos es más bien muy escasa, especialmente para bacilos gramnegativos.

Lamentablemente, a pesar de todo este cúmulo de evidencias en relación a esta urgencia de salud pública, la respuesta en nuestro país ha sido más bien limitada, habiendo poco avance en medidas para su control y prevención, aun considerando que nuestro país es líder en control de infecciones. Así, la resistencia bacteriana continúa en aumento y no se han implementado programas que nos permitan evaluar con datos de buena calidad y en tiempo oportuno nuestra situación epidemiológica, así como tener respuesta organizada con medidas de control adecuadas para contrarrestar este problema. Por lo tanto, el cometido es urgente y nuestro compromiso no puede esperar.

Gracias al exitoso Programa Nacional de Infecciones Intrahospitalarias, en Chile disponemos de información local y nacional relacionada a tasas de infecciones asociadas a procedimientos invasores y la microbiología relacionada a ellos. También disponemos de información referente a la organización de los hospitales en términos de la preparación para el control de las infecciones intrahospitalarias. Sin embargo, a pesar de grandes esfuerzos de grupos locales o incluso de las sociedades cientificas, en Chile la información de resistencia bacteriana disponible hasta la fecha ha sido parcial, intermitente y, la mayor de las veces, no es representativa de lo que pasa en el medio nacional. Así, escasamente disponemos de datos más representativos sólo a partir del año 2004.

Desde ese año se ha venido realizando en la localidad de Santa Cruz, Colchagua, un curso-taller anual para abordar el tema de la resistencia antimicrobiana, actividad que en sus orígenes estuvo ligada a la industria farmacéutica, pero que con el paso del tiempo y gracias a un esfuerzo conjunto de sus organizadores y participantes, ha logrado desarrollar una agenda propia, donde la participación interdisciplinaria y el espíritu de colaboración han sido fundamentales.

Este curso-taller ha tenido la particularidad de reunir y hacer dialogar de manera efectiva, tanto a los microbiólogos que cuantifican y evalúan la resistencia bacteriana, como a los médicos clínicos encargados de tratar las infecciones y velar por el correcto cumplimiento de las medidas de prevención de infecciones en los hospitales, que es precisamente el lugar donde se genera el problema. Así, gracias a la mencionada interacción de especialistas, el grupo mismo ha fijado tareas y objetivos cuyo producto inicial, referido a las tasas nacionales de resistencia del año 2009, se muestran con orgullo en este número de la revista.

Esta información es valiosa, pues representa información actual y de un número representativo de hospitales de distinto tipo de nuestro país. Sin embargo, tiene algunas limitaciones que los autores mencionan con claridad en el texto. Estas limitaciones resultan de la fuente de la información, debido a que los datos son obtenidos a través de los métodos habitualmente usados en los distintos laboratorios, sin una metodología depurada y pre-establecida como la requerida para redes creadas para este propósito. 
Si se desea que el grupo genere información relacionada a resistencia no sólo debemos limitarnos a cuantificar el problema, sino también debemos evaluar los factores de riesgo y las estrategias implementadas para su control. Así, nos deberíamos acercar cada vez más a la meta de lograr un control efectivo de la resistencia bacteriana en nuestro país.

Para ir detrás de estos objetivos, es tiempo de dar un paso adelante y organizarnos con este propósito. Debemos aprovechar el gran capital creado y cristalizarlo en la formación de un Grupo Colaborativo de Resistencia Bacteriana, el cual, como fue deseo de sus miembros, forme parte de la Sociedad Chilena de Infectología. Según la definición, trabajo colaborativo se usa para designar el entorno en el cual todos los participantes de un grupo trabajan, colaboran y se ayudan para la realización del proyecto. Así, este grupo de trabajo representa aproximadamente 25 hospitales del país, número que se espera ir ampliando en el futuro. El propósito y compromiso será difundir el diagnóstico de situación y actualizar los datos en forma periódica. El ideal es que este esfuerzo sea seguido de las necesarias acciones educativas a todo nivel, que involucre a distintos agentes del área médica y de la comunidad.

Este grupo debería ser incluyente de todos los agentes involucrados en este tema, tanto las instituciones gubernamentales (particularmente el Instituto de Salud Pública), las sociedades científicas, las universidades y, principalmente, los hospitales que no sólo son la célula donde se genera la información, sino que son aquellos más impactados con el problema de la resistencia en nuestro país. Este esfuerzo debería complementar la regulación en la comunidad de la venta de antimicrobianos, actividad que ya cuenta con un respaldo legal desde 1999.

Nuestra visión es que este grupo sea capaz de generar información de la mejor calidad, lo más oportuna y representativa posible, para que finalmente se logren establecer los mecanismos correctos para disminuir la resistencia bacteriana en nuestros hospitales. Sólo ahi podremos decir que este grupo colaborativo sirvió al objetivo fundamental en el área de las enfermedades infecciosas en nuestro país.

Deberíamos asumir este tema como sugieren las palabras de J. F. Kennedy, "Some see things as they are and ask why. (Others) see things as they should be and ask why not". 